\title{
Cyclic rectification technology in column mass exchange apparatuses with perforated plates
}

\author{
Yuriy Buliy, Anatoly Kuts \\ National University of Food Technologies (NUFT), Kyiv, Ukraine
}

\begin{abstract}
Proposed below is the technology of cyclic rectification at continuous supply of heating steam to the mass exchange column apparatus equipped with perforated plates. The method allows to prolong the time of contact of steam and liquid on plates up to 40-60 s and reduce the time of overflow up to 1-2 s. Hydrodynamic modes of operation of perforated plates are determined to ensure their cyclic action: the lower critical velocity of steam in barbotage openings of meshes plates is 5,4 $\mathrm{m} / \mathrm{s}$, of scalesplates is $6,5 \mathrm{~m} / \mathrm{s}$; the upper critical velocity at which fluid is carried away is 8 and $16 \mathrm{~m} / \mathrm{s}$, respectively. A prerequisite for spilling the liquid through barbotage openings is an instantaneous reduction of the steam velocity in the openings to $1,5-1 \mathrm{~m} / \mathrm{s}$ due to the instantaneous change of the free cross-section of the plate from 2,6 to 51,7\% and more. Efficiency research of the offered technology was carried out in industrial conditions in processes of distillation of alcoholcontaining fractions and epuration of alcoholic fermentations distillates in the experimental column. It has been established that the technical solution allows to increase the degree of separation of higher alcohols of fusel oil and methanol by $38 \%$, to increase the multiplicity of the concentration of head impurities by $25 \%$, the upper intermediate impurities - by $40 \%$ and the end impurities - by $37 \%$. In such conditions, the specific consumption of heating steam in the separating column decreases from 25 to $16 \mathrm{~kg} / \mathrm{dl}$ of anhydrous alcohol introduced on the acceptance plate, and in the epurational column - from 15 to $8,2 \mathrm{~kg} / \mathrm{dl}$ of anhydrous alcohol.

Keywords: rectification, column, alcohol, impurity.
\end{abstract}

Corresponding author: Yuriy Buliy

E-mail: yvbuliy@gmail.com

DOI: $10.24263 / \mathrm{RES}-2019-7$

\section{Introduction}

In columns with mass transfer on perforated plates, vapours and liquids pass through the same holes or slots. These plates are called perforated plates. These include scales, meshes, tubular, wavy and other plates. Advantages of perforated plates simplicity of a design, low cost of manufacturing and installation, rather small hydraulic resistance. The main drawback is the short speed change interval of steam and liquid within which steady and efficient operation is maintained, insufficient time of contact of phases, also agitation of liquid on adjacent plates. 
The authors proposed the technology of cyclic rectification, which provides for continuous supply of heating steam in the mass-exchanging column apparatus with barbotage-perforated plates. The innovative technology provides the implementation of controlled cycles of liquid retention on perforated plates and its periodic overflow through all the openings from the upper plates to the lower ones due to the instantaneous change of steam speed. While the liquid is retained on the plates, there is a mass transfer between the liquid and the steam, which goes through the contact device holes. During this cycle period, the floating valve closes the overflow port and the fluid is held on the plate. When the overflow opening is opened, the steam velocity in the barbotage openings becomes lower than the critical speed at which it is held on the plate and the liquid is transferred to the lower plates. The versatility of the operation of the barbored-perforated plates is in the alternation of the steam velocity in the contact device holes by changing the free cross-section of the plates in a given range of values according to a given algorithm (Patent of Ukraine \# 89874, Patent of Ukraine \# 136560). With aforementioned conditions, the driving force of the mass transfer process increases due to the increase in the concentration gradient of volatile components, improves the diffuse characteristics of contact devices, the efficiency of operation increased and the specific flow rate of heating steam is reduced $[2,4,6,9]$.

The aim of the research is conditioned by the definition of the hydrodynamic mode of operation of barbotage perforated plates, of the efficiency of the technology of cyclic rectification in the mass-exchange columns equipped with barbotage perforated plates with variable free cross-sectionin and determining the consumption of heating steam in the separating and epurational columns.

\section{Materials and methods}

Research methods - analytical, chemical, physico-chemical with the use of instruments and research methods used in the production of rectified ethyl alcohol. Fluid consumption was controlled with the help of flowmeter RM, air velocity in the free section of the column - anemometer MS-13, in the holes of the plates - by calculation method. The concentration of volatile impurities of alcohol was determined on a gas chromatograph with a column HP FFAP $50 \mathrm{~m} \times 0.32 \mathrm{~m}$.

Analysis of research samples was performed according to gas chromatographic method for determination of microcomponents content $[10,11]$.

\section{Results and discussions}

Operation efficiency of barbotage perforated plates in conditions of cyclic rectification depends on the adopted hydrodynamic regimes that determine the boundaries of stable operation of mass transfer tower apparatuses. The necessary condition for their determination is the establishment of the maximum allowable steam velocity (upper and lower critical velocity) in the free section of the column and 
barbotage holes. The lower limit corresponds to the steam velocity at which the "sink" of the liquid from the upper plates to the lower ones stops, the upper limit corresponds to the steam velocity at which the liquid from the lower plates begins to drift to the upper ones, which leads to a reduction of the phase contact surface.

The research was carried out on an experimental rectification column equipped with replaceable contact devices - meshes and scales in the water-air system. Characteristics of the column: diameter $-300 \mathrm{~mm}$; number of plates -5 pcs.; distance between plates $-300 \mathrm{~mm}$; diameter of barbotage holes $-2,4 \mathrm{~mm}$; area of section of holes of arched type scales $-19,42 \mathrm{~mm}^{2}$; thickness of a cloth of a plate $-2 \mathrm{~mm}$; free section of a plate $-2,6 \%$; height of a layer of a liquid on plates $-35 \mathrm{~mm}$. For the meshes plates the air flow rate was changed in the range of $1-15 \mathrm{dm}^{3} / \mathrm{s}$, which corresponds to the change of speed in the barbotage openings of 1,5-10 m/s, the irrigation density fluctuated in the range of 4 to $11 \mathrm{~m}^{2} /\left(\mathrm{M}^{2} \mathrm{~h}\right)$. For scales plates the irrigation density varied from 5 to $15 \mathrm{~m}^{3} /\left(\mathrm{M}^{2} \mathrm{~h}\right)$.

It is known that in order to increase the efficiency of plate of various designs it is advisable to delay the liquid on their canvas by organizing the flow of separate vaporliquid jets with mutual collision of jets or additional installation of partitions and reflectors. Liquid brake devices are made in the form of holes, nozzles, etc. The area of free cross-section of holes with a counter flow of steam is $2-3 \%$ of the total area of the plate. To increase the duration of the contact between steam and liquid and to intensify the mass transfer, vertical dividers are installed in some areas of the plate [19].

In spite of positive results, proved by methods of mathematical modeling, the known methods and models have not found wide practical application because of complexity of the chosen constructive decisions, absence of mass exchange in the steam period, fluctuations of pressure of steam in a collector and low throughput of column mass exchange apparatuses on steam and a liquid.

In order to solve the set tasks the authors proposed the technology of cyclic rectification, which allows to exclude the above mentioned disadvantages, and the construction of a column mass exchange apparatus equipped with perforated plates of cyclic action. The method provides for periodic overflow of liquid from the plate to the plate due to the forced operation of overflow devices containing moving elements associated with the drive mechanisms (Patent of Ukraine \# 116565). To implement the technology, the column apparatus will be equipped with mesh or scale-shaped plates with coaxial arrangement of scales. Such technical solution allows to exclude unidirectionality of steam and liquid flows over the whole area of the plate, and in case of separation of mixtures containing suspended particles (for example, in the braga column of the distillation unit), to exclude the possibility of formation of stagnant zones, sticking of suspended particles on the surface of the plates and thus to increase their service life without stopping for preventive work.

For realization of the offered method and carrying out of researches of a plate of an experimental column have been equipped by the rotary segments equipped with microprocessor pneumatics of firm FESTO (connected to standard pneumocylinders 
of bilateral action of type DNT 63-50-PPV-A) which moved in turns according to the program of controller M340 of firm "Schneider Electric" [5, 6, 9]. Movable segments opened and closed the overflow openings of the plates in such a way that the liquid overflow occurred periodically from top to bottom in the height of the column (Figure $1)$.



Figure 1. Cyclic plate with scales and variable free cross section:

1 - plate; 2 - turning segment; 3 - drive mechanism; 4 - scales

The column includes plates 1 and movable segments of plates 2 associated with the drive mechanisms 3 . On the plates 1 and segments 2 are placed scales 4 so that the direction of the scales arranged in one row is opposite to the direction of the scales located in adjacents rows. The mass transfer contact plate works as follows. Liquid enters the sheet 1 of plate No. 1 from above the located plate No. 2 through the overflow hole, which is formed after the opening of the movable segment 2. During this period, the movable segment of the web 1 of the plate No. 1 is closed for a specified period of time. From the bottom upwards, heating steam flows continuously through the scales' 
slots and comes into contact with the liquid on the plate web. Mass exchange between liquid and steam takes place in barbotage mode. After the set time of liquid delay, the moving segment 2 of plate No. 1 is opened, and the liquid is poured to the bottom of the plate through the hole, which was formed, and spilled through all the slots of the scales (Patent of Ukraine \# 136561).

At the first stage of researches hydrodynamic modes of stable work of mesh and scaly plates in a mode of controllable cycles of a delay and overflow of a liquid have been established, maximum admissible values of speed of air in barbotage apertures and in a free section of a column at which the liquid is kept on plates and at which its carrying away (ejection) on the top plates begins are defined. It is established that the lower critical air velocity in the barbotage openings of meshes plates $\left(V_{\text {hole }}\right)$ was 5,4 $\mathrm{m} / \mathrm{s}$; the linear air velocity in the free section of the column $\left(V_{\text {lin }}\right)-0,25 \mathrm{~m} / \mathrm{s}$. For scales plates: $\left(V_{\text {hole }}\right)$ is equal to $6,5 \mathrm{~m} / \mathrm{s}$; in barbotage mode of plate $\left(V_{\text {lin }}\right)$ was $0,5-0,9 \mathrm{~m} / \mathrm{s}$, in transition $-0,9-1,3 \mathrm{~m} / \mathrm{s}$ and in jet $-1,3-2,0 \mathrm{~m} / \mathrm{s}$.

At the second stage of the studies, the air velocity in the bubbling holes $\left(V_{\text {drift }}\right)$ was determined, at which the entrainment of liquid onto the upper plates began. In the columned apparatus with meshes plates $\left(V_{\text {drift }}\right)$ was $8 \mathrm{~m} / \mathrm{s}$; while $\left(V_{\text {lin }}\right)$ was equal to 0,7 $\mathrm{m} / \mathrm{s}$; the relative value of fluid entrainment (e) did not exceed $0,01 \mathrm{~kg}$ per $1 \mathrm{~kg}$ of air. In a column with scales plates $\left(V_{\text {lin }}\right)$ was equal to $1,3-1,5 \mathrm{~m} / \mathrm{s}$; in mode of barbotage not more than $0,1 \mathrm{~kg} / \mathrm{kg}$, in jet mode $-0,2 \mathrm{~kg} / \mathrm{kg}$. Intense fluid overflow was observed at steam speeds below critical. For perforated plates the steam speed should not exceed $1,5-1 \mathrm{~m} / \mathrm{s}$. The obtained experimental data can be used in the development of mass transfer apparatus with perforated plates operating in a cyclic mode of rectification.

Research of efficiency of the offered technology was carried out in production conditions of Stonibabsky place of business of the State Enterprise Ukrspirt in processes of distillation of alcohol-containing fractions and epuration of distillate in a hydroselection mode. For research, an experimental cyclic column with perforated plateswas mounted (Figure 2).

The column had a diameter of $950 \mathrm{~mm}$ and was equipped with scales in the amount of 30 pieces. The distance between the plates was $300 \mathrm{~mm}$. Rotating segments of the plates were connected to mechatronic subsystems, which were controlled by modern computer-integrated means. 




Figure 2. Experimental cyclic column with perforated plates

During the periodic movement of the rotating segments alternately opened and closed the overflow holes of the plates according to the given algorithm in such a way that the overflow of liquid occurred cyclically along the height of the column from top to bottom with the continuous movement of steam from bottom to top. When the overflow opening was opened by the movable segment, the free area of the plate instantly changed from 2,6 to $51,7 \%$. As a result, the steam velocity in the barbotage openings became less than $1,5-1,0 \mathrm{~m} / \mathrm{s}$, and the liquid simultaneously overflowed through the overflow opening and fell through all the openings. The technical solution made it possible to intensify the overflow process, reduce the overflow time to 1-2 s and increase the throughput capacity of the column apparatus.

The head fraction of ethyl alcohol and the alcohol-containing fractions from the condensers of the fermentation column, carbon dioxide separator, fusel alcohol, washing fusel water and streams from alcohol traps were fed into the column. The total supply volume was $688,3 \mathrm{dm}^{3} / \mathrm{h}$ or $250 \mathrm{dm}^{3} / \mathrm{h}$ in terms of anhydrous alcohol (a.a). The upper plate of the column continuously received hot softened water in the amount of $4050-4500 \mathrm{dm}^{3} / \mathrm{h}$ for hydroselection of impurities. The specified water consumption 
provided concentration of ethyl alcohol in a cube liquid within the limits of 3,5-3,8\% vol. Under such conditions, the distillation coefficient of all impurities of alcohol (including higher alcohols of fusel oil) exceeded one, and impurities were effectively released. The cube liquid released in the process of distillation from volatile impurities was supplied to the upper zone of the concentration part of the epuration column for double hydroselection of head impurities and effective extraction together with the head fraction of isopropyl alcohol. Such a solution allowed to reduce the consumption of hot softened water for hydroselection of impurities to $2000 \mathrm{dm}^{3} / \mathrm{h}$. The retention time of the liquid on the plates was 40-60 s, the time of its overflow was 1-2 s.The pressure in the cub part of the column was maintained within 1,15-1,20 meters of the water column, the temperature was $100,5-101{ }^{\circ} \mathrm{C}$, the temperature above the upper plate was $93,5-94{ }^{\circ} \mathrm{C}$. Aldehyde-methanol concentrate was taken from the upper stage condenser in the amount of 7-9 $\mathrm{dm}^{3} / \mathrm{h}$. Esters and higher alcohols of sea liquor oil were taken out of the unit from the upper decanting zone in the form of ester-sivushnogo concentrate in the amount of $2-3 \mathrm{dm}^{3} / \mathrm{h}$ after the separation of the water-alcohol mixture. Aldehyde-methanol and estero-sivushy concentrates were mixed in the admixture concentrate collector.

In the course of the research, samples of feed $(F)$, cube fluid $(C L)$, impurity concentrate $(I C)$, euphrates $(E)$, head fraction $(H F)$ and rectified ethyl alcohol $(R A)$ were taken. The results of chromatographic analysis of the research samples and calculated values of the extraction degree $(\alpha)$ and multiplicity of concentration $(\beta)$ volatile alcohol impurities at the operation of the perforated plates in the selected hydrodynamic mode, and the separating column at the above technological parameters are given in tabl.1.

Table 1

Results of the chromatographic analysis of the test samples and the calculated values of the degree of extraction ( $\alpha$ ) and the multiplicity of concentration $(\beta)$ of volatile impurities of alcohol

\begin{tabular}{|l|c|c|c|c|c|c|c|c|}
\hline \multirow{2}{*}{$\begin{array}{c}\text { A group of } \\
\text { impurities }\end{array}$} & \multicolumn{6}{|c|}{ Concentration, $\mathrm{mg} / \mathrm{dm}^{3}$ in terms of a.a. } & \multirow{2}{*}{$\alpha$} & \multirow{2}{*}{$\beta$} \\
\cline { 2 - 9 } & $\mathrm{F}$ & $\mathrm{CL}$ & $\mathrm{IC}$ & $\mathrm{E}$ & $\mathrm{HF}$ & $\mathrm{RA}$ & & \\
\hline Ethanol,\% oб. & 30,5 & 3,7 & 67 & 30,1 & 92,5 & 96,5 & 8,2 & 2,2 \\
\hline Aldehydes & 318,6 & 2,75 & 2302 & 0,29 & 1135 & 0,18 & 115,9 & 7,2 \\
\hline Esters & 40,5 & - & 448615 & - & 2395 & - & $\infty$ & 11077 \\
\hline Methanol,\% & 0,18 & 0,0003 & 2,69 & 0,0023 & 0,49 & 0,0003 & 600 & 14,9 \\
\hline Fusel oil & 105882 & 726,9 & 726463 & 1179,8 & 3113 & 0,88 & 145,7 & 6,9 \\
\hline
\end{tabular}

The analysis of the received results has shown that at prolongation of time of stay of a liquid on sagging plates up to $40 \mathrm{~s}$ ester and isopropyl alcohol are completely removed. It is known that by the content of isopropanol the quality and power of distillation units are estimated. The degree of extraction of higher alcohols of fusel oil and methanol increased by $38 \%$, the multiplicity of concentration of head impurities 
increased by $25 \%$, of upper intermediate impurities - by $40 \%$, of end impurities - by $37 \%$ in comparison with a typical installation operating in stationary mode. It is established that in the cyclic mode of rectification the specific consumption of heating steam in the process of distillation of alcohol-containing fractions decreased from 25 to $16 \mathrm{~kg} / \mathrm{dl} \mathrm{a.a.,} \mathrm{introduced} \mathrm{on} \mathrm{the} \mathrm{feeding} \mathrm{plate,} \mathrm{and} \mathrm{in} \mathrm{the} \mathrm{process} \mathrm{of} \mathrm{epuration} \mathrm{of} \mathrm{draga}$ distillate - from 15 to $8,2 \mathrm{~kg} / \mathrm{dl}$ a.a. in comparison with column apparatuses operating in stationary mode. After inclusion of an experimental acceleration column in the scheme of distillation unit the output of distilled ethyl alcohol increased by 3,8\%. According to all indicators, the ethyl distilled alcohol obtained met the requirements for the variety «Lux».

The expected payback period of the upper stage does not exceed 5 months.

\section{Conclusion}

The authors proposed the technology of cyclic rectification in column apparatuses equipped with barbotage perforated plates with variable free cross-section. Experimental data of the maximum permissible steam velocity in the free section of the column and barbotage openings of meshts and scales plates during the period of mass transfer and liquid overflow are obtained.

It is established that the increase of the time of liquid stay on the plates up to 40$60 \mathrm{~s}$ in the chosen hydrodynamic mode allows to increase the degree of extraction and the multiplicity of concentration of head, intermediate and end impurities by $25-40 \%$, and the instantaneous change of the steam speed in the barbotage holes below the critical one allows to reduce the liquid overflow time to 1-2 s and thus to increase the throughput of the column apparatus. Due to the increased phase contact time, the specific heating steam consumption in the processes of distillation of alcoholic fractions and epuration of fermented distillate is reduced by at least $36 \%$ in comparison with column units operating in stationary mode.

The expected payback period of the proposed energy-saving mass transfer column apparatuses of cyclic action does not exceed 5 months.

\section{Referenses}

1. Bildea C.S., Patrut C., Jorgensen S.B., Abildskov J., Kiss A.A., (2016), Cyclic distillation technology - A minireview, Journal of Chemical Technology and Biotechnology, 91, pp. 1215-1223.

2. Kiss A. A., Bildea C. S. (2011), A control perspective on process intensification in dividing-wall columns, Chemical Engineering and Processing: Process Intensification, 50, pp. 281-292. 
3. Kiss A.A., Landaeta F., C.J., Zondervan E. (2012), Cyclic distillation - towards energy efficient binary distillation, Chemical Engineering and Chemistry, 30, pp. 697-701.

4. Krivosheev V., Anufriev A. (2015), Fundamentals and efficiency of cyclic modes of rectification process. Basic Research, Scientific Journal of Basic Research, 11(2), pp. 267-271.

5. Pătruţ C., Bîldea C. S., Liţă, I., Kiss A. A. (2014), Cyclic distillation - Design, control and applications, Separation and Purification Technology, 125, pp. 326336.

6. Lita I., Bildea C.S., A.A. Kiss A.A. (2014), Catalytic cyclic distillation - A novel process intensification approach in reactive separations, Chemical Engineering and Processing, 81, pp. 1-12.

7. Nielsen R.F., Huusom J.K., Abildskov J. (2017), Driving force based design of cyclic distillation, Industrial \& . Engineering Chemistry Research, 56, pp. 1083310844.

8. Premkumar R., Rangaiah G.P. (2009), Retrofitting conventional column systems to dividing-wall columns, Chemical Engineering Research and Design, 87 (1), pp. 47-60.

9. Simon L.L., Kencse H., Hungerbuhler K. (2009), Optimal rectification column, reboiler vessel, connection pipe selection and optimal control of batch distillation considering hydraulic limitations, Chemical Engineering and Processing, 48, pp. 939-949.

10. Charapitsa S.V., Bychkov, S.M., Kavalenka A.N., Mazanik A. L., Selemina, N.M., Sholomitskii K.V. (2003), Main component (solvent) as internal standard for chromatographic quantitative analysis of impurities, Abstr. Pittsburgh Conf. on Anal. Chem. Appl. Spectroscopy, Orlando, Florida, pp. 526527.

11. Charapitsa S.V., Bychkov, S.M., Kavalenka A.N., Mazanik A. L., Selemina, N.M., Sholomitskii K.V. (2003), The use of the major component (solvent) as an internal standard in the gas-chromatographic determintion of impurities, $J$. Anal. Chem., 58, pp. 368-371. 